\title{
VIDA, LIBERDADE E PROPRIEDADE: RAWLS E KANT A PARTIR DA PERSPECTIVA DE PAUL GUYER
}

\author{
LIFE, LIBERTY AND PROPERTY: RAWLS AND KANT FROM THE PERSPECTIVE \\ OF PAUL GUYER
}

\author{
NELSI KISTEMACHER WELTER ${ }^{1}$ \\ (UNIOESTE / UFSC - Brasil)
}

\begin{abstract}
RESUMO
O propósito deste artigo é o de apresentar alguns elementos de relação entre Kant e Rawls a partir da perspectiva de Paul Guyer. Segundo Guyer, antes de Rawls o pensamento kantiano influenciou muito pouco o pensamento político americano. Mas a partir de Rawls esta realidade muda significativamente justamente porque, de acordo com Guyer, a teoria da justiça como equidade é derivada de uma concepção essencialmente kantiana. Mais do que isso, os princípios de justiça de Rawls correspondem, hoje, à reconstrução apropriada para a concepção do direito de Kant.

Palavras-chave: Vida, Liberdade, Propriedade, Princípios de Justiça, Pensamento Kantiano.
\end{abstract}

\begin{abstract}
This article aims to present some elements of the relation between Kant and Rawls from the perspective of Paul Guyer. According to Guyer, before Rawls, the Kantian thought had influenced very little the American political thought. But from Rawls, this reality changes significantly precisely because, according to Guyer, the theory of justice as fairness is derived from an essentially Kantian conception. More than that, Rawls's principles of justice correspond, today, to the appropriate reconstruction to Kant's right conception.
\end{abstract}

Keywords:Life, Freedom, Property, Principles of Justice, Kantian Thought.

\section{APRESENTAÇÃO DO PROBLEMA}

\subsection{Kant e o pensamento político americano}

Paul Guyer acredita que, antes de Rawls, o pensamento kantiano tenha influenciado muito pouco a filosofia política americana. Isto porque a estrutura básica do pensamento político americano foi desenvolvida entre 1770 e 1780, alguns anos antes de a Doutrina do Direito de Kant ter sido publicada. A Constituição americana é ligeiramente anterior ao trabalho de Kant.

A Declaração da Independência de 1776 e a Constituição de 1787 incluem entre os fins do governo a promoção da felicidade ou bem estar de seus cidadãos, tanto quanto a preservação de suas vidas e a garantia de sua liberdade. Um governo verdadeiramente representativo é aquele que promove efetivamente a felicidade daqueles que representa, assim como também defende suas vidas e a sua liberdade. A Declaração dos Direitos dos Estados Unidos (United States Bill of Rights), 
adicionada à Constituição americana, poderia ser tomada como defensora de certas liberdades civis fundamentais, às quais a promoção da felicidade e do bem estar das pessoas devem estar sempre subordinadas. Por esse motivo, a Declaração dos Direitos poderia ser tomada como tendo introduzido uma ordem léxica em relação às duas metas - de preservação da liberdade e promoção da felicidade e do bem estar.

A filosofia política de Kant, porém, limita o fim legítimo de qualquer governo à defesa da vida e da liberdade dos sujeitos, sendo-lhe vedado qualquer esforço no sentido de promover o bem estar ou a felicidade das pessoas que representa. O papel do governo está restrito à defesa da liberdade, de tal forma a salvaguardar a liberdade de todos os cidadãos para que os mesmos possam perseguir a sua felicidade a partir de sua própria concepção. O Estado não deve ter como sua meta a promoção do bem estar ou da felicidade em qualquer sentido que seja, mas apenas a garantia da liberdade. Em outras palavras, o Estado não pode coagir as pessoas a serem felizes, mas cada um deve buscar a felicidade da forma que lhe pareça melhor, desde que não prejudique a liberdade dos outros de buscar um fim similar. Kant posiciona-se claramente contrário ao governo paternalista, por considerá-lo despótico.

Kant estabelece um limite entre o estabelecimento da justiça compreendido como garantia dos direitos inalienáveis à vida e à liberdade por um lado, e o direito à felicidade e à promoção do bem estar geral, por outro lado, ambos conjugados como fins igualmente legítimos do governo na tradição constitucional americana. De acordo com Guyer, torna-se assim difícil perceber a relação entre a filosofia política aplicada à Constituição americana e a filosofia política de Kant (GUYER, 2000: 264).

A partir de Rawls, no entanto, esta realidade muda de maneira significativa. Em 1971, John Rawls publica $A$ Theory of Justice, obra que, segundo Guyer, teria recebido forte influência do pensamento de Kant, implicando, conseqüentemente, na atribuição de elementos kantianos à filosofia política americana.

O que Rawls teria herdado de Kant? Qual é a influência kantiana no pensamento americano, se é que há alguma influência?

\subsection{A justiça como equidade e a constituição americana}

Segundo Paul Guyer em Kant on Freedom, Law and Happiness, a concepção rawlsiana da “justiça como equidade”, composta pelos dois princípios de justiça - cuja ordenação serial subordina o segundo ao primeiro - é derivada, supostamente, de uma concepção essencialmente kantiana dos agentes morais livres e iguais. A concepção rawlsiana, segundo Guyer, fornece subsídios para 
a concepção americana dos fins do governo como originalmente estabelecida pela Declaração da Independência e então modificada pela emenda à Constituição com a Declaração de Direitos dos Estados Unidos. De acordo com a última, um governo justo é aquele que protege as liberdades de todos e intervém no que diz respeito às desigualdades na distribuição dos bens primários, de tal forma a maximizar o bem estar dos membros menos favorecidos da sociedade, considerando, porém, que a segunda meta é sempre limitada pela primeira.

Paul Guyer interpreta os princípios rawlsianos como refletindo a ideia de que a proteção da liberdade, juntamente com a promoção do bem estar geral, constituem os fins legítimos do governo, constituindo, consequentemente, uma declaração de direitos civis invioláveis, que jamais poderão ser ultrapassados, nem mesmo em prol do interesse de promover o fim último (GUYER, 2000: 265-266).

Mas o que há de kantiano na concepção rawlsiana da justiça social? O que Rawls faz, na melhor das hipóteses, não é apenas introduzir um princípio kantiano de prioridade da liberdade numa concepção não kantiana dos fins do governo? Não estaria Rawls introduzindo um princípio não kantiano ao permitir a intervenção do governo nas desigualdades econômicas e sociais, melhorando a situação dos menos favorecidos?

\subsection{A concepção rawlsiana e a compatibilidade com Kant}

De acordo com Guyer, não há incompatibilidade entre a concepção dos princípios de justiça rawlsianos e a concepção kantiana da esfera limitada de governo. O que ocorre, acrescenta ele, é que a concepção de justiça de Rawls é, na verdade, determinada pela concepção kantiana (GUYER, 2000: 266).

De acordo com a interpretação de Guyer, a análise da propriedade na Doutrina do Direito de Kant, volta-se à necessidade de garantia da liberdade para a aquisição de propriedade, transformando-a na principal razão para a criação e manutenção do Estado ${ }^{2}$. Contudo, acrescenta ainda que um sistema de propriedade pode ser racionalmente e moralmente aceito pelos cidadãos de um Estado apenas quando entra em jogo o interesse de todos que serão afetados por ele. Desta reivindicação poderia ser extraída a seguinte interpretação: na distribuição da propriedade as igualdades são aceitáveis racionalmente apenas quando são para o interesse de todos os afetados por elas, incluindo os menos favorecidos. Neste sentido, o segundo princípio de justiça rawlsiano é, portanto, afirma Guyer, compatível com a concepção kantiana da relação entre a propriedade e o Estado. Assim, a concepção da justiça social de John Rawls, juntamente com seus dois princípios de justiça, acompanhado, ainda, de sua ordem lexicográfica, podem ser concebidos como uma 
reconstrução plausível da filosofia política kantiana, embora o próprio Rawls nunca tenha apelado diretamente aos textos de filosofia política de Kant para fundamentar seu pensamento, mostrandose inspirado apenas nas características básicas da abordagem geral da filosofia moral kantiana (GUYER, 2000: 266-7).

Entretanto, diz Guyer, é importante esclarecer que mesmo que se admita que os princípios rawlsianos de justiça sejam uma reconstrução compatível com a concepção kantiana do direito externo, além de considerar que estes forneçam um modelo filosófico para os princípios básicos do constitucionalismo americano, isso não implica, necessariamente, em que se possa deduzir que a filosofia kantiana e o pensamento filosófico americano sejam correspondentes. Na concepção da Declaração da Independência de 1776 há uma ênfase muito forte na busca da felicidade, com a qual Kant não concorda. Qualquer idéia de que o governo poderia participar diretamente na busca da felicidade, desde que não desrespeite qualquer um dos direitos civis invioláveis, traz dificuldades frente à concepção kantiana, que não concorda com uma imposição paternalista da felicidade como fim do governo. É melhor sugerir, afirma Guyer, que a reconstrução rawlsiana apresenta uma relação muito forte entre a concepção kantiana do que concerne legitimamente ao Estado e a concepção lockeana dos fins do governo que, por sua vez, inspirou a Declaração da Independência.

\section{A PROPOSTA DE JOHN RAWLS}

\subsection{Rawls e o contratualismo}

O contrato social é tomado como eixo da teoria rawlsiana da justiça - a justiça como equidade. O contrato possui, em Rawls, uma estrutura formal, além de que, partindo da hipótese de um contrato fictício, permite explicar um sistema normativo existente. A pretensão rawlsiana, ao recorrer a este instrumento conceitual, é de resolver e elucidar questões substantivas próprias da sociedade contemporânea e da sua organização estrutural.

Rawls denomina a sua versão do contratualismo de kantiana, partindo da idéia puramente hipotética da "posição original", na qual o objeto de acordo são os princípios de justiça. Os princípios escolhidos na "posição original" devem ser aplicados às instituições que formam a estrutura básica da sociedade.

No Prefácio de Uma teoria da justiça sua intenção em relação ao contratualismo é expressa da seguinte maneira: "Minha tentativa foi de generalizar e elevar a uma ordem mais alta de abstração a teoria tradicional do contrato social representada por Locke, Rousseau e Kant" (RAWLS, 1997: xxii). 
Já no 33 da mesma obra, Rawls diz que o mérito da utilização da teoria contratualista está no fato de que torna possível a pessoas racionais a escolha de princípios de justiça, além de permitir, conseqüentemente, a explicação e justificação das concepções de justiça escolhidas. Trata-se de um acordo que implica pluralidade. Os princípios de justiça, acerca dos quais se produz o acordo, tratam, justamente, dos benefícios obtidos através da cooperação social. Dessa maneira, para que não haja conflito, é necessário que a divisão desses benefícios ocorra em conformidade com princípios que sejam aceitos por todas as partes contratantes. Além disso, o contratualismo rawlsiano também implica a publicidade dos princípios escolhidos. Assim, se os princípios resultam de um acordo entre as partes, todos têm conhecimento dos princípios que são seguidos.

\subsection{A equidade na posição original}

A posição original é uma situação equitativa entre as pessoas em suas relações mútuas, na medida em que são tomadas como pessoas morais, ou seja, como pessoas racionais, que possuem seus próprios objetivos e, além disso, são capazes de um senso de justiça em tal situação. A equidade representa o traço mais característico da situação em que é justo o acordo do qual resultam os princípios de justiça. Ou seja, o papel da posição original deve situar pessoas iguais de maneira equitativa, transferindo-se esta equidade das circunstâncias em que é feito o acordo aos próprios princípios que serão escolhidos (Cf. RAWLS, 1980: 522).

No texto "Kantian Constructivism in Moral Theory", Rawls explica que incorpora a ideia da justice processual pura como característica da posição original e que esta permita a caracterização das partes igualmente autônomas, enquanto agentes racionais do processo de construção. $\mathrm{O}$ uso da justiça processual pura implica que os princípios de justiça são construídos através de um processo de deliberação na posição original. Nesse processo, o peso que possuem as considerações favoráveis ou contrárias aos princípios acerca dos quais se delibera é dado pelo peso que possuem para as partes - enquanto agentes que deliberam - e o peso final é estabelecido com o acordo que é feito pelas mesmas.

A exposição e justificação da teoria rawlsiana da justiça através do "método da justiça processual pura" tem por propósito a simples aplicação de um procedimento que deva produzir um resultado justo. Ou seja, a idéia da justiça processual pura, aplicada à posição original, garante que quaisquer que sejam os princípios escolhidos nesta situação serão justos.

O recurso de Rawls ao véu da ignorância é fundamental, pois ele garante a imparcialidade na medida em que encobre as partes contratantes, impedindo que saibam sua identidade particular. Além disso, o véu de ignorância procura garantir que as informações a que as partes têm acesso na 
posição original sejam relevantes e que sejam sempre as mesmas.

O véu de ignorância impede que modelemos nossa visão moral de acordo com nossos interesses e vínculos particulares. Não analisamos a ordem social a partir de nossa situação, mas assumimos um ponto de vista que todos podem adotar em pé de igualdade. Neste sentido, consideramos nossa sociedade e nosso lugar dentro dela de forma objetiva: partilhamos com os outros um ponto de vista comum, e não fazemos nossos julgamentos assumindo um viés pessoal (RAWLS, 1997: 575).

As restrições em relação a certas informações específicas têm importância fundamental, já que sem elas não seria possível a elaboração de uma teoria da justiça. Por isso, são introduzidos certos limites ao conhecimento das partes para, com isso, tornar possível a escolha unânime de uma determinada concepção de justiça.

\subsection{Os princípios de justiça}

Considerando-se que as partes, na posição original, sejam racionais e que possuem um desinteresse mútuo, essas...

(...) tentam reconhecer princípios que promovem seus sistemas de objetivos da melhor forma possível. Elas fazem isso tentando garantir para si mesmas o maior índice de bens sociais primários ${ }^{3}$, já que isso lhes possibilita promover a sua concepção de bem de forma efetiva, independentemente do que venha a ser essa concepção (RAWLS, 1997: 155).

A versão final dos princípios de justiça selecionados na posição original pode ser visualizada no $\$ 46$ de Uma teoria da justiça:

Primeiro princípio: Cada pessoa deve ter um direito igual ao mais abrangente sistema total de liberdades básicas iguais que seja compatível com um sistema semelhante de liberdades para todos.

Segundo princípio: As desigualdades econômicas e sociais devem ser ordenadas de tal modo que, ao mesmo tempo:

(a) tragam o maior benefício possível para os menos favorecidos, obedecendo às restrições do princípio da poupança justa, e 
(b) sejam vinculadas a cargos e posições abertos a todos em condições de igualdade eqüitativa de oportunidades (RAWLS, 1997: 333).

O primeiro princípio recebe a denominação de "princípio de igual liberdade" e exige que as liberdades sejam aplicadas a todos igualmente e que sejam as mais extensas possíveis. Através do primeiro princípio estão garantidas as seguintes liberdades: a liberdade política, juntamente com a liberdade de expressão e de reunião; a liberdade de consciência e de pensamento; a liberdade da pessoa e o direito de possuir propriedade; além da liberdade contra a prisão arbitrária.

O segundo princípio é dividido em duas partes: "o princípio da diferença" e o "princípio da igualdade de oportunidades". O princípio da diferença trata da distribuição da riqueza e do rendimento, defendendo que, embora a distribuição desses elementos não tenha que ser igual, ela deve ocorrer de tal forma que maximize as expectativas dos que são menos beneficiados. Já o princípio da igualdade de oportunidades trata das diferenças de autoridade e responsabilidade, sendo que as mesmas devem ser acessíveis a todos.

Rawls considera os bens naturais como um bem comum, de maneira que os benefícios de sua distribuição devem ser compartilhados por todos. Além disso, as pessoas não são merecedoras de seus talentos e capacidades ou da situação social em que nascem. Não se trata de justiça ou injustiça, mas de uma espécie de loteria natural. As instituições sociais, no entanto, podem ser consideradas justas ou injustas, dependendo do modo como agem em relação a esses fatos naturais.

A organização da estrutura básica deve se dar de tal maneira a neutralizar os efeitos decorrentes de tais contingências. Nesse sentido, as instituições sociais básicas devem levar aqueles que têm mais a compensar aos que têm menos - e que também não são merecedores desta situação - e dar mais atenção aos que nasceram em situações sociais menos favorecidas. Segundo Rawls, "os que foram favorecidos pela natureza, sejam eles quem forem, podem beneficiar-se de sua boa sorte apenas em termos que melhorem a situação dos menos felizes” (RAWLS, 1997: 108).

Os dois princípios de justiça estariam ordenados lexicalmente, segundo Rawls, de tal forma que, em primeiro lugar, devem satisfazer-se as exigências da liberdade. Nenhum outro princípio pode ser invocado enquanto não forem satisfeitas tais exigências. Isso significa que, quando se colocam as condições para o estabelecimento das liberdades básicas, não é permitido “(...) trocar uma liberdade menor ou desigual por uma melhoria no bem-estar econômico" (RAWLS, 1997: 164). O acordo que é feito acerca do princípio da igual liberdade não pode ser revogado, o que significa que esse não pode ser relativizado para que se obtenham meios mais importantes com vistas à promoção de outros interesses. A obtenção de uma quantidade maior de benefícios econômicos e sociais em troca de uma liberdade desigual é inconcebível. 
A ordenação lexicográfica dos princípios implica que não se possa renunciar a nenhuma das liberdades fundamentais, por maiores que possam ser os benefícios do ponto de vista sócioeconômico. A limitação dos direitos básicos só pode ser admitida quando as circunstâncias sociais não permitirem que estes direitos sejam efetivamente estabelecidos. No entanto, mesmo neste caso, as restrições só poderão ser admitidas se elas forem necessárias para se criar uma situação em que isso deixe de existir. Em relação ao segundo princípio, a parte (b) é anterior à parte (a). Rawls pretende que a hierarquia entre os princípios seja respeitada no momento da sua aplicação.

\subsection{A argumentação em favor dos dois princípios}

A concepção da justiça como eqüidade possui diversas vantagens positivas. No $§ 29$ de Uma teoria da justiça, Rawls apresenta três considerações relevantes em defesa dos princípios de justiça. A primeira diz respeito ao senso de justiça de que as pessoas são dotadas e de acordo com o qual só podem fazer acordos quando são capazes de honrá-los, mesmo que as circunstâncias que se apresentem posteriormente sejam as piores possíveis. Em segundo lugar, a justiça como eqüidade é a concepção preferida por Rawls por gerar seu próprio apoio, garantindo a sua estabilidade. Em terceiro lugar, o reconhecimento público dos dois princípios de justiça dá uma sustentação maior ao respeito próprio das pessoas e esse, por sua vez, reflete na efetividade da cooperação social.

Rawls ainda acrescenta à defesa dos princípios aquilo que ele domina de argumentação a partir de uma concepção de moralidade explicitamente kantiana. Vamos conhecer alguns desses elementos.

De acordo com o autor de "Uma teoria da justiça", “(...) os princípios manifestam, na estrutura básica da sociedade, o desejo dos homens de tratar uns aos outros não apenas como meios, mas como finalidades em si mesmos" (RAWLS, 1997: 195). É preciso compreender essa noção - de que os homens devem ser tratados como fins em si mesmos e não apenas como um meio - a partir da interpretação contratualista, que implica em “(...) tratá-los de acordo com os princípios com os quais eles consentiriam em uma posição original de igualdade” (RAWLS, 1997: 195). Na posição original, os homens possuem igual representação na condição de pessoas morais e os princípios aceitos serão formulados racionalmente, tendo em vista a proteção de suas reivindicações. Eis o sentido em que as pessoas devem ser tratadas como fins e não simplesmente como meios.

Novamente, temos a confirmação dos dois princípios rawlsianos como a melhor escolha e que assegura o interesse racional de cada pessoa. O primeiro princípio garante que todos tenham liberdades básicas iguais, enquanto o segundo nos permite interpretar a diferença entre tratar os homens meramente como meios ou tratá-los como fins em si mesmos. Vejamos: 
Considerar as pessoas como fins em si próprias na concepção básica da sociedade é concordar em abdicar dos ganhos que não contribuem para as expectativas de todos. Em contraste com isso, considerar as pessoas como meios é estar disposto a impor àqueles já menos favorecidos perspectivas ainda mais baixas de vida, em favor das expectativas mais altas de outros (RAWLS, 1997: 196).

Temos, assim, segundo Rawls, uma interpretação bastante razoável para o princípio da diferença.

Passaremos agora a conhecer um pouco mais a interpretação de Paul Guyer, indicando em que sentido Kant teria influenciado a teoria da justiça como eqüidade.

\section{A INFLUENCIA DE KANT NA TEORIA DA JUSTIÇA COMO EQUIDADE: A INTERPRETAÇÃO DE PAUL GUYER}

Considerando os princípios da justiça como equidade e a afirmação de que estes podem ser obtidos a partir de nossa concepção moral enquanto seres livres e iguais e, além disso, considerando que a prioridade do primeiro princípio sobre o segundo possa ser obtida a partir do valor do autorespeito, Guyer afirma não restar dúvida alguma de que estes elementos (especialmente o argumento da prioridade da liberdade como a condição fundamental do auto-respeito) estão corretos da perspectiva kantiana sobre a função última do princípio da moralidade.

Paul Guyer cita o argumento kantiano de Lectures on Ethics, segundo o qual “(...) os deveres para consigo mesmo constituem a condição suprema e o princípio de toda a moralidade (...)”, porque, acima de tudo, “(...) devemos venerar a humanidade na nossa própria pessoa, por que de outra forma o homem torna-se um objeto de desprezo, insignificante aos olhos de seus companheiros e insignificante para si mesmo (...) (apud GUYER, 2000: 275). Assim, a base para a moralidade é estabelecida, nas palavras de Guyer, precisamente no contraste entre o tratamento dado a nós mesmos meramente como instrumentos naturais para obter prazer sensual e o auto-respeito que conduz a viver de acordo com o ideal de ação livre e racional, na qual somos fins e nunca meramente meios. Consequentemente, a moralidade kantiana está baseada na suposição de que podemos respeitar a nós mesmos apenas ao procurarmos viver de acordo com o ideal da racionalidade livre, cujas diretrizes para a realização são expressas pela lei moral.

Levemos em conta, então, o argumento rawlsiano segundo o qual seus princípios de justiça são justamente aqueles obtidos por pessoas buscando dar expressão ao ideal moral de que elas próprias e os outros são pessoas igualmente racionais e livres. Da perspectiva kantiana, afirma Guyer, restaria ainda a questão de se esses princípios morais da justiça social podem tornar-se 
"leis externas" do "direito público", ou seja, se podem ser considerados princípios fundamentais da organização política. Seguindo a argumentação kantiana, tem-se a questão se pessoas livres e racionais estão dispostas a aprovar a "aplicação coercitiva" (coercive enforcement) dos princípios rawlsianos de justiça. Enquanto para Kant esta questão da coerção é fundamental, já que constitui a essência da lei externa, para Rawls, no entanto, não se coloca a questão da coerção na busca pela expressão social de nossa concepção moral acerca de nós mesmos.

A ideia de lei externa em Kant admite o uso da sanção coercitiva para a sua realização. Mais do que isso, a coerção, na perspectiva de Kant, não só é permissível como é necessária enquanto obstáculo à limitação ou perda da liberdade.

Guyer acredita que um sujeito racional, concebendo-se a si mesmo como pessoa livre e igual a todos os outros em relação a seu direito à liberdade, concordaria com a defesa, mesmo que à força, da igual liberdade máxima, na medida em que teme que outra pessoa possa reduzir a sua liberdade. A aplicação coercitiva do segundo princípio por pessoas morais e racionais, porém, não lhe parece tão clara. Se o princípio da diferença apenas pudesse ser imposto pela coerção, pareceria ser o caso precisamente em que o princípio da diferença seria realizado apenas às custas de uma redução da liberdade de alguém, violando, portanto, a prioridade do princípio da igual liberdade em relação ao princípio da diferença. Dessa forma, pessoas racionais prefeririam ver o princípio da diferença realizado, mas não aceitariam a sua execução coercitiva. Conseqüentemente, o segundo princípio de justiça descreveria “(...) um ideal desejável de moralidade social sem dar origem a uma verdadeira lei pública executável coercitivamente” (GUYER, 2000: 276). A concepção rawlsiana de justiça “(...) pareceria ser um ideal de moralidade social genuinamente kantiano, mas ultrapassando as fronteiras dos deveres de direito genuinamente kantianos" (GUYER, 2000: 276-277).

O problema levantado por Paul Guyer em Life, Liberty, and Property no que diz respeito à concepção de propriedade em Kant aponta para a necessidade de algo muito semelhante ao princípio da diferença para a distribuição dos bens primários de renda e riqueza. Assim, se o pensamento kantiano aceita o estabelecimento coercitivo e a manutenção da instituição da propriedade por meio do instrumento do Estado, como ocorre, também deve estar preparado para sustentar “(...) a aceitação coercitiva de algo como o princípio da diferença" (GUYER, 2000: 277). Assim, embora Kant tenha boas razões para resistir à inclusão da busca da felicidade em geral entre os fins de um governo justo, por outro lado, ele próprio está comprometido com a “(...) aplicação de um princípio justo para a distribuição da propriedade como parte dos fins próprios do governo” (GUYER, 2000: 277).

Seguindo a interpretação de Paul Guyer, o princípio do direito ou da justiça é definido em Kant apenas em termos da preservação da liberdade: "Uma ação é conforme ao Direito quando permite ou quando a sua máxima permite fazer coexistir a liberdade do arbítrio de cada um com a liberdade de todos segundo uma lei universal" (KANT, $A A 230 ; 43)^{5}$. 
De acordo com Paul Guyer, temos aí um acordo com o princípio da justiça de Rawls, segundo o qual: "cada pessoa deve ter um direito igual ao mais abrangente sistema de liberdades básicas iguais que seja compatível com um sistema semelhante de liberdade para as outras" (RAWLS, 1997: 64). Se o único motivo para a restrição da liberdade de alguém é a compatibilidade com a liberdade dos outros, o resultado, então, seria a máxima preservação compatível da liberdade de todos (GUYER, 2000: 277). Devido à sua identidade, a concepção de Kant acerca do direito externo parece estar confinada ao primeiro princípio.

A restrição do conceito de justiça por manter aquela liberdade assim tão limitada pela possibilidade de igual liberdade para os outros é o único direito "inato" ou original pertencendo a cada homem em virtude de sua humanidade.

Kant aponta diversos significados do direito inato, entretanto não explica porque ou em que sentido ele é inato ou original. Provavelmente o que ele tenha em mente é simplesmente que a base para todos os nossos "deveres perfeitos para com os outros", a única forma de dever segundo a qual o constrangimento de legislação externa pode estar relacionada, é o dever para preservar e proteger de injúria a liberdade de outros e seu ser físico e moral, na medida em que é uma condição de sua liberdade. No entanto, tal dever perfeito pode originar uma determinada reivindicação ou direito por parte dos outros para que sua liberdade não seja destruída ou diminuída, reivindicação essa que, consequentemente, é fisicamente possível e moralmente permissível aplicar. Em contraste, nosso dever imperfeito para promover ou melhorar as condições sob as quais outros podem usar sua liberdade não origina nenhuma obrigação de executar ações particulares em seu interesse em nenhuma circunstância especial e, portanto, não pode originar nenhuma reivindicação ou direito moralmente impositivo de sua parte.

O próximo passo na teoria da justiça de Kant é a reivindicação de que "o Direito está associado à autorização para o uso de coerção". Sua argumentação se coloca da seguinte maneira:

A resistência que se opõe à obstacularização de um efeito fomenta esse efeito e concorda com ele. Ora, tudo aquilo que é não conforme com o Direito é um obstáculo à liberdade segundo leis universais; mas a coerção é um impedimento ou resistência com que se defronta a liberdade (KANT, $A A: 231 ; 44)$.

Dessa forma, na medida em que um determinado uso da liberdade se apresenta, ele próprio, como um obstáculo à liberdade (consequentemente em desacordo com o Direito) a coerção que se apresenta, então, impedindo a limitação à liberdade, está em conformidade com a liberdade e, consequentemente, em conformidade com o Direito. Em outras palavras, a coerção que se opõe à coerção, impedindo a limitação da liberdade, concorda com a liberdade sendo, por esse motivo, 
permitida e, melhor ainda, acaba tornando-se necessária para a preservação da liberdade.

Este argumento de Kant, no entanto, é muito simples, afirma Guyer, de tal forma que fica aberto a objeções. Segundo ele, a coerção opondo-se à limitação da liberdade é realmente consistente com a liberdade e não teria ela mesma o efeito de reduzir ou destruir a liberdade enquanto obstáculo que ela está tentando impedir.

Entretanto, Guyer reforça a argumentação. Em primeiro lugar, um ato inicial que impediria a liberdade dos outros reduzindo ou destruindo-a não é ele mesmo um uso da liberdade compatível com a liberdade igual dos outros e, desta forma, não está protegido pelo Princípio Universal do Direito. Em segundo lugar, poder-se-ia também argumentar que a ameaça da coerção opondo-se à limitação da liberdade não priva ela mesma o pretenso executor do impedimento inicial à limitação de sua própria liberdade sendo, em consequência, consistente com ela. Em vez disso, enquanto o executor que simplesmente reduziria a liberdade do outro não dá ao outro nenhuma escolha a esse respeito, a ameaça da coerção em relação a um tal executor o leva, juntamente com a escolha livre, a desistir ou sofrer as consequências de seu ato; de tal forma que o executor não está de fato privado de sua liberdade no sentido que sua vítima estaria. Nesse caso, então, um impedimento à limitação da liberdade é, na verdade, consistente com a sua preservação, podendo ser autorizado e até requerido em nome do dever perfeito e do direito inato à liberdade.

O próximo passo apontado por Guyer na argumentação kantiana trata da introdução do direito à propriedade. No "Postulado da razão prática no que tange aos direitos" podemos visualizar a argumentação kantiana. $\mathrm{O}$ argumento de Kant consiste basicamente em defender que seria irracional ou contraditório à liberdade privar-se do uso de objetos utilizáveis, pois estaria, ela mesma, privando-se de fazer uso do seu arbítrio em relação a um objeto de sua própria escolha (KANT, $A A: 246 ; 69)$. Em outras palavras, a razão ordena que sejam criadas condições a partir das quais os objetos possam ser usados por agentes particulares na perseguição de seus vários fins. Os agentes devem ter o poder de planejar sobre o uso ou disposição de objetos que não estão em sua posse física atualmente.

Para Kant, a aquisição jurídica de uma coisa ocorre independentemente do Estado. Entretanto, a aquisição de uma coisa própria é provisória no estado de natureza, tornando-se peremptória apenas com a constituição do Estado. Assim, é a ocupação que garantirá o título de aquisição originária à propriedade, conforme podemos ver no $\S 14$ da Doutrina do Direito: “A aquisição de um objecto exterior do arbítrio mediante uma vontade unilateral é a ocupação. Portanto, a aquisição originária deste objeto e, bem assim, de um solo determinado só mediante ocupação (occupatio) pode ter lugar" (KANT, $A A: 263 ; 96)$.

Entretanto, a aquisição originária através da posse física atribui um "título empírico" ao objeto de posse, sendo tal posse apenas provisória, podendo se tornar definitiva apenas na condição 
civil. O título de posse só pode ser considerado racional na condição civil, tornando-se a aquisição, consequentemente, definitiva.

A chave para a argumentação kantiana, segundo Guyer, está aí: a condição para a posse inteligível de algo exige o consentimento dos outros para quaisquer reivindicações de propriedade individual por razões ontológicas e morais (GUYER, 2000: 280).

Kant afirma que “a questão ‘como são possíveis um meu e um teu exteriores?' resolve-se na questão 'como é possível uma posse meramente jurídica (inteligível)? (...)" (KANT, AA: 249; 75). No $§ 8$ encontramos, de maneira resumida, o motivo expresso por Kant para tal afirmação:

\begin{abstract}
Se declaro (verbalmente ou por actos): quero que algo exterior seja meu, declaro que qualquer outro está obrigado a abster-se do objecto do meu arbítrio; obrigação essa que ninguém teria sem este meu acto jurídico. Mas nesta pretensão está ínsito igualmente o reconhecimento de estar reciprocamente obrigado em relação a qualquer outra pessoa a uma abstenção semelhante, no que respeita ao seu exterior; pois que a obrigação dimana aqui de uma regra universal da relação jurídica exterior (KANT, $A A: 255 ; 85$ ).
\end{abstract}

Temos aqui um argumento que precisa ser compreendido em duas etapas. A primeira etapa está relacionada à suposição de que, na medida em que a posse da propriedade deve envolver mais que o mero controle físico momentâneo da mesma, ela deve, em vez disso, consistir no reconhecimento do direito de alguém prescrever o uso de um objeto sobre o qual ninguém exerce posse física atualmente, que corresponde a nada menos que o acordo dos outros para que tenha tal direito. Assim, o consentimento dos outros para o controle da propriedade é uma condição de possibilidade da existência da propriedade necessária ontologicamente e trata-se apenas do reconhecimento dos outros que estendem a posse para além do mero controle físico.

Entretanto, temos aí tanto uma implicação moral quanto pragmática. Ninguém tem direito moral de reivindicar o consentimento dos outros para o controle de propriedade a não ser que haja um direito semelhante de controle de propriedade para os outros. Da mesma maneira, ninguém tem nenhuma razão pragmática para esperar que as outras pessoas concordem que alguém tenha o controle de qualquer propriedade se este mesmo acordo não fizer parte de um sistema de direitos de propriedade que é suficientemente vantajoso para todos. Isso só seria possível se este acordo fosse obtido por meio da pura coerção o que, no entanto, é problemático, já que a coerção só é justificada como um impedimento à limitação da liberdade.

Segundo Guyer seria irracional negar a si mesmo o tipo de uso de objetos a longo prazo que a propriedade admite, mas a pessoa só tem esse direito na medida em que o mesmo pode ser estendido para os outros. 
Frente ao apelo geral da reciprocidade dos direitos de propriedade, Kant não detalha muito as condições sob as quais é razoável consentir para um sistema de tais direitos. Todavia, Guyer defende que o princípio da diferença de Rawls é uma interpretação plausível das condições sob as quais seria moralmente permissível exigir o acordo de todos para um sistema de distribuição de bens e com o qual seria racional concordar.

Partindo de uma perspectiva puramente pragmática, se todos os membros da sociedade sabem que mesmo que ocupem a posição mais desfavorecida na sociedade, que eles ainda estarão em melhor situação sob o sistema de propriedade proposto do que sob qualquer outra forma de distribuição de bens e, além disso, sabem que não há nenhum impedimento socialmente institucionalizado para alterar suas posições de tal forma que possam ainda aproveitar as oportunidades que o sistema oferece, não haveria, portanto, nenhuma razão para não concordar com tal princípio. Entretanto, observa Guyer, restrições mais fracas em relação à distribuição de bens que a rigorosa restrição do princípio da diferença de Rawls também poderiam tornar racional o consentimento em relação a um sistema de direitos de propriedade. No entanto, a análise que Kant faz da propriedade não somente requer que calculemos pragmaticamente sob quais condições é razoável esperar que os outros consintam em relação às nossas reivindicações de propriedade como também requer que consideremos o que é moral exigir dos outros. Guyer acrescenta: poderíamos argumentar que a moralidade de exigir o consentimento dos outros requer um nível mais elevado de igualdade do que a consideração mais puramente pragmática a respeito do nível de igualdade necessário para obter o consenso efetivo (GUYER, 2000: 282). Poder-se-ia ainda sustentar que a exigência de moralidade, que serve igualmente para o interesse de todos, inicia por requerer que o consentimento ocorra pelo interesse dos que se encontram em pior situação. Desta maneira, mesmo se o princípio da diferença não resultar apenas de considerações pragmáticas, ele pode ser defendido como resultante de coações morais que buscam o consentimento das pessoas para as reivindicações de propriedade.

Resumindo, então, Kant estabelece, de maneira geral, que não é possível estabelecer razoavelmente um direito de propriedade em relação a mim mesmo sem o consentimento dos outros e, além disso, que estes darão o consentimento apenas na medida em que o sistema de direitos de propriedade (system of property rights) implicar o seu próprio interesse da melhor maneira possível. $\mathrm{O}$ direito à propriedade é tomado, em outras palavras, como um exercício da própria liberdade de alguém, mas apenas nas condições em que se esteja propenso a conceder um direito análogo de propriedade aos outros.

Guyer conclui então que o direito à propriedade em Kant não pode ser subordinado a um princípio de liberdade, semelhante ao primeiro princípio de justiça em Rawls, a não ser que também se reconheça algo muito semelhante ao segundo princípio de justiça rawlsiano (GUYER, 2000: 282). Entretanto, temos ainda o problema de reconhecimento em relação aos dois princípios de justiça rawlsianos no sentido de considerá-los como princípios do direito externo (external law) ou 
justiça pública, no sentido kantiano de serem executáveis através da coerção.

A conclusão de Guyer deriva da suposição kantiana de que os direitos de propriedade só podem ser estabelecidos dentro de um Estado e que ninguém possui o direito de coagir quaisquer outros que, na qualidade de membros de um Estado, possam interferir no uso de objetos com o propósito de estabelecer direitos de propriedade.

A propriedade só pode existir pelo acordo mútuo ou vontade de todos e não por um ato de vontade unilateral e individual, já que desta maneira não poderíamos obrigar os outros. Além disso, a vontade de todos está unida na forma da lei na condição civil. Dessa maneira, a propriedade só pode existir numa condição civil ou sob regras do direito.

Guyer acredita que provavelmente Kant tenha em mente os postulados tradicionais de acordo com os quais tanto a lei atual quanto o consentimento geral são necessários simultaneamente para estabelecer reivindicações de propriedade. Entretanto, Kant não pretende afirmar que os direitos de propriedade sejam prioritários logicamente ao estabelecimento do Estado e que o papel deste seja apenas melhorar ou consolidar tais direitos (GUYER, 2000: 283). Sua argumentação segue no sentido de afirmar que sem o Estado tais direitos são apenas provisórios, consistindo na antecipação e com a disposição de contribuir para as leis de um estado disposto a reconhecer o direito de propriedade na medida em que este direito se estende a todos.

A parte mais complicada da argumentação é a que diz respeito à coerção, já que é onde serão consideradas as bases morais para o consentimento em torno de um sistema de propriedade.

De acordo com Kant, alguém que reivindica direitos de propriedade provisoriamente com uma disposição de unir-se num estado que estabeleceria tais direitos para si mesmo e para os outros, tem o direito de resistir que os outros cometam injúria em relação à sua propriedade, mas mesmo de coagi-los a unirem-se a ele em tal estado. No $\S 9$ da Doutrina do Direito podemos ver a argumentação em defesa do direito de resistência aos possíveis ataques em relação às reivindicações de propriedade provisória, ou seja, antes do ingresso na condição civil:

\footnotetext{
Antes da entrada nesse estado, para a qual o sujeito está disposto, ele opõe-se com razão àqueles que a tal se não conformam e que o querem perturbar na sua posse provisória; porque a vontade de todos os demais com excepção dele próprio, que pensa colocá-lo sob a obrigação de se abster de certa posse, é meramente unilateral, e, portanto, tem tão pouca força legal (a qual só se encontra na vontade universal) para se opor como aquela para afirmar; não obstante o facto de que a última tem a vantagem de concordar com a implantação e a edificação de um estado civil (KANT, $A A$ : 257; 87).
}

Assim, se uma pessoa quiser ter propriedade para si mesma sem, no entanto, reconhecer 
também a minha reivindicação por propriedade, então ela simplesmente estaria limitando minha liberdade ao invés de reconhecê-la, podendo ser, portanto, impedida coercitivamente. Entretanto, uma vez que reivindico propriedade apenas na medida em que também reconheço o direito de propriedade do outro, não estou limitando a sua liberdade e não caio, portanto, sob a mesma regra de restrição. Consequentemente, só é possível justificar minha resistência coercitiva em nome da liberdade, mas o ataque a mim não o é.

A reivindicação posterior de Kant é de que uma pessoa não só tem o direito de reagir ao ataque às suas reivindicações de propriedade provisória, como também pode coagir legitimamente outras pessoas com as quais mantém contato para juntarem-se a ele numa condição civil:

(...) pois que, embora cada um possa, segundo este ou aquele conceito de Direito que perfilhe, ter adquirido algo exterior por via de ocupação ou de contrato, essa aquisição é apenas provisória enquanto não obtida em seu favor a sanção de uma lei pública (...) (KANT, $A A: 312 ; 177$ ).

Dessa maneira, justifica-se a necessidade do estado civil:

(...) é necessário sair do estado de natureza, em que cada um age como lhe dá na cabeça, e unir-se a todos os demais (com quem não se consegue evitar entrar em interação) para se submeter a uma coerção externa legislada publicamente, portanto, entrar num estado em que cada um se determine por lei e se lhe atribua por meio de um poder suficiente (que não seja o seu próprio, mas um exterior) o que deve ser reconhecido como seu, quer dizer, que deve entrar, antes de mais, num estado civil (KANT, $A A: 312 ; 176-7)$.

No estado de natureza ninguém está livre de temer por sua propriedade, mesmo que não se depare com o estado de guerra. A argumentação de Kant prossegue indicando que as pessoas têm um direito à propriedade na medida em que admitem um direito similar para os outros; consequentemente, o mesmo se dá em relação à propriedade dos outros, que só pode ser assegurada pelo estabelecimento do estado civil. Dessa maneira, a criação de tal estado é a extensão legítima de sua liberdade. Além disso, as pessoas não pretendem injuriar as outras ao buscarem a criação de uma tal condição, pois, na medida em que querem estender para si o direito à igual propriedade de si mesmo, não fariam nenhuma injúria ao exercício legítimo de sua própria liberdade.

Sair do estado de natureza e entrar num estado civil é correto e, mais ainda, obrigatório, de tal forma a evitar-se a ameaça da injúria, e ninguém tem nenhuma razão para resistir ao Estado, já que nele cada um tem o mesmo direito que os outros.

Por conseguinte, é injusta a resistência coercitiva ao estabelecimento de um estado que 
tornaria peremptórias as reivindicações de propriedade provisórias, porque seria uma violação unilateral da liberdade. Entretanto, o estabelecimento coercitivo do estado civil não é injusto, porque ele realmente estenderia a oferta de liberdade para o uso e aquisição de propriedade (GUYER, 2000: 284-5). Ter-se-ia, assim, o direito de impor a criação de um estado reconhecendo direitos de propriedade como uma extensão racional da liberdade individual, mas apenas na medida em que o direito à propriedade é estendido a todos nos termos que cada um pode concordar racionalmente.

De acordo com Guyer, a conclusão kantiana aponta para o fato de que pode haver uma legislação externa ou pública que faça respeitar o direito à propriedade, mas isso só é possível em condições de igualdade como aquelas descritas pelo segundo princípio de justiça de John Rawls. Dessa forma, se temos em vista o sentido kantiano de um princípio de liberdade externa obrigatório coercitivamente, poderíamos apontar para a necessidade de algo como o segundo princípio, tanto quanto o primeiro princípio de justiça rawlsiano.

Paul Guyer acredita, então, ter completado a sua argumentação no sentido de apontar os princípios rawlsianos de justiça como a reconstrução da concepção de direito de Kant e, assim, que mesmo não havendo nenhuma influência entre a filosofia política kantiana e a filosofia política do constitucionalismo americano, não há, porém, nenhum conflito entre ambos, pelo menos da forma como é reconstruído por Rawls (GUYER, 2000: 285).

Guyer acrescenta ainda um comentário final envolvendo o tema Kant e o liberalismo. Sugere que a justaposição entre o anti-paternalismo kantiano, tal como expresso em Teoria e Prática, sobretudo, e o comprometimento com algo parecido com o princípio da diferença de Rawls originado na teoria da propriedade da Doutrina do Direito não estão em conflito efetivamente, mas antes apresentam o modelo para resolver a natureza aparentemente paradóxica do liberalismo político. A argumentação de Kant defende sim que é despótico o governo que interfere nas concepções de felicidade de seus cidadãos, bem como suas crenças, convicções e metas individuais. Entretanto, é justo que o governo interfira na distribuição dos recursos que são os meios para a felicidade.

Enquanto ninguém necessita do consentimento de qualquer outra pessoa para suas crenças e convicções, bem como sua concepção de felicidade, por outro lado, cada pessoa necessita do consentimento de todos os outros para suas reivindicações de propriedade. Entretanto, só é possível esperar e exigir tal consentimento, na medida em que também se está disposto a consentir com um sistema de propriedade que seja justo para todos, condição essa que só pode ser realizada através da instrumentalização de um sistema de direito civil público.

Para Guyer, embora na prática possa parecer paradoxal para o liberalismo, por um lado, insistir na máxima liberdade de crença, mas, por outro lado, intervir na distribuição da riqueza e do rendimento, teoricamente não haveria aí nenhum paradoxo, pois que a liberdade de crença e a liberdade de reivindicar propriedade possuem condições de possibilidade ontológicas e morais fundamentalmente 
diferentes.

\section{CONSIDERAÇÕES FINAIS}

Não obstante a pretensão de Guyer, qual seja, de defender que, apesar de não podermos atribuir a formulação da Constituição americana ao pensamento kantiano, a mesma teria sofrido forte influência de Kant, todavia, através do pensamento de John Rawls. Mesmo que nos pareça claro que não tenha sido a intenção do autor de Uma teoria da justiça simplesmente desenvolver fundamentos filosóficos para o sistema constitucional americano, cumpre-nos ressaltar que o pensamento rawlsiano, apesar de ter recebido uma série de acusações neste sentido, certamente ultrapassou, e muito, as fronteiras dos EUA desde seu surgimento. Na obra O liberalismo político podemos ver sua intenção claramente expressa: "O problema do liberalismo político consiste em formular uma concepção de justiça política para um regime democrático constitucional que a pluralidade de doutrinas razoáveis (...) possa endossar" (RAWLS, 2000: 26). E continua afirmando que “(...) o objetivo do liberalismo político consiste em descobrir em que condições é possível haver uma base de justificação pública razoável no tocante a questões políticas fundamentais" (RAWLS, 2000: 27).

O construtivismo político de Rawls, diferentemente do construtivismo moral de Kant que se estabelece como doutrina abrangente, representa o modelo teórico que pretende buscar um consenso mínimo entre diferentes doutrinas morais, filosóficas e religiosas abrangentes, de tal forma que estas possam coexistir numa sociedade democrática liberal, sob uma concepção de pluralismo razoável. Assim, o objetivo de Rawls está muito aquém das pretensões de Kant. Através do procedimento construtivista kantiano é estabelecido o conteúdo da lei moral. Em Rawls, o que se constrói é a concepção política de justiça, cujo conteúdo implica nos dois princípios de justiça escolhidos na posição original. O construtivismo kantiano se apresenta, para o filósofo americano, como uma terceira via entre as concepções teleológicas (éticas das virtudes e utilitarismo) e intuicionistas. Dessa maneira, considerando o fato do pluralismo razoável que marca a sociedade, a pretensão rawlsiana é de oferecer um modelo para a fundamentação pública da justificação de questões de filosofia política.

$\mathrm{Na}$ leitura que faz da importância da tese rawlsiana, o professor Nythamar de Oliveria vai além, afirmando que o que Rawls pretende através da teoria da justiça como eqüidade é “(...) provernos com uma concepção ético-política dos fundamentos normativos da vida social" (OLIVEIRA, 2006: 36). Mais do que isso, podemos ver a teoria da justiça,

(...) como um procedimento universalizável de construção capaz de dar conta da 
sociabilidade humana em sociedades democráticas regidas por uma constituição, onde reivindicações de liberdades básicas e de participação eqüitativa na vida social permitem a convivência pluralista de diversas doutrinas religiosas, filosóficas e morais (OLIVEIRA, 2006: 36).

A teoria da justiça como eqüidade se volta, portanto, para as sociedades democráticas, cujo pluralismo razoável constitui uma condição permanente. Ou seja, a cultura política pública de uma sociedade democrática é marcada pela diversidade de doutrinas religiosas, filosóficas e morais como característica permanente. Dado que não é possível haver acordo de todos os cidadãos em torno de uma doutrina abrangente (seja ela religiosa, filosófica ou moral), surge então a necessidade, apontada por Rawls, da idéia de um consenso sobreposto. Tal consenso buscará fazer da concepção política um ponto de vista comum, ao mesmo tempo em que tal concepção política se encontra alicerçada em doutrinas religiosas, filosóficas e morais razoáveis, embora opostas. Com isto, teremos, de acordo com Rawls, condições para estabelecer uma base mais razoável para a obtenção de unidade política e social para os cidadãos de uma sociedade democrática. 


\section{NOTAS}

${ }^{1}$ Doutoranda em Filosofia na UFSC; professora da UNIOESTE.

${ }^{2}$ No capítulo VII de Kant on Freedon, Law and Happiness, cujo título é "Kant Foundations for Liberalism", Guyer dedica-se a analisar o tema da propriedade em Kant.

${ }^{3}$ A ideia de bens primários está ligada, segundo Rawls, à concepção que define as pessoas como possuidoras de certos interesses de ordem superior (ligados à personalidade moral e à necessidade de garantia de sua concepção de bem). As partes vão buscar garantir, através da lista de bens primários, aquelas condições necessárias para o exercício das capacidades que os caracterizam como pessoas morais.

${ }^{4}$ Tradução nossa.

${ }^{5}$ Em relação às referências bibliográficas relativas à Kant, atribuiremos a paginação da Academia, acompanhada da paginação do texto traduzido. 


\section{REFERÊNCIAS}

DANIELS, Norman. Reading Rawls. Stanford: Stanford University Press, 1989.

GUYER, Paul. Life, Liberty, and Property. In: Kant on Freedom, Law and Happiness. Cambridge: Cambridge University Press, 2000.

KANT, Immanuel. A metafísica dos costumes. Trad. José Lamego. Lisboa: Fundação Calouste Gulbenkian, 2005.

KYMLICKA, Will. “The Social Contract Tradition”, In: SINGER, Peter. A companion to Ethics. Cambridge: Basil Blackwell, 1994.

OLIVEIRA, Nythamar de. A concepção normativa de pessoa e sociedade em Kant e Rawls: uma interpretação semântico-transcendental. In: Dissertatio, 24, 2006. p. 23-40.

OLIVEIRA, Nythamar de. Rawls. Rio de Janeiro: Jorge Zahar, 2003.

OÑA, Fernando Vallespín. Nuevas Teorías del Contrato Social. Madrid: Alianza Editorial, 1985.

RAWLS, John. A Theory of Justice. Cambridge: Harvard University Press, 1971 (Versão Brasileira: Uma Teoria da Justiça. Trad. Almiro Pisetta e Lenita M. R. Esteves. São Paulo: Martins Fontes, 1997).

RAWLS, John. Justiça como eqüidade: uma reformulação. São Paulo: Martins Fontes, 2003.

RAWLS, John. Kantian Constructivism in Moral Theory. In: The Journal of Philosophy, v. 77, n. 9, set./1980. p. 515-72 (Versão Brasileira: O Construtivismo Kantiano na Teoria Moral. In: Justiça e Democracia. Trad. Irene A. Paternot. São Paulo: Martins Fontes, 2000. p. 43-140).

RAWLS, John. Political Liberalism. 2 ed. New York: Columbia University Press, 1996 (Versão Brasileira: O Liberalismo Político. 2 ed. Trad. Dinah de Abreu Azevedo. São Paulo: Ática, 2000.).

ROHDEN, Valério. Interesse da razão e liberdade. São Paulo: Ática, 1981. 